\title{
Jianpi Huayu Decoction Inhibits Proliferation in Human Colorectal Cancer Cells (SW480) by Inducing Go/G1-Phase Cell Cycle Arrest and Apoptosis
}

\author{
Song-yang Xi, ,,2 Yu-hao Teng, ${ }^{1,2}$ Yan Chen,, ${ }^{1,2}$ Jie-ping Li, ${ }^{1,2}$ Ying-ying Zhang, \\ Shen-lin Liu, ${ }^{1}$ Xi Zou, ${ }^{1}$ Jin-yong Zhou, ${ }^{1}$ Jian Wu, ${ }^{1}$ and Rui-ping Wang ${ }^{1}$ \\ ${ }^{1}$ The Affiliated Hospital of Nanjing University of Chinese Medicine, Nanjing, Jiangsu 210029, China \\ ${ }^{2}$ Nanjing University of Chinese Medicine, Nanjing, Jiangsu 210023, China \\ Correspondence should be addressed to Rui-ping Wang; wrp61@163.com
}

Received 29 July 2015; Accepted 7 September 2015

Academic Editor: Shao-Hsuan Kao

Copyright (c) 2015 Song-yang Xi et al. This is an open access article distributed under the Creative Commons Attribution License, which permits unrestricted use, distribution, and reproduction in any medium, provided the original work is properly cited.

Jianpi Huayu Decoction (JHD), a Chinese medicine formula, is a typical prescription against multiple tumors in the clinical treatment, which can raise quality of life and decrease complications. The aim of this study is to assess the efficacy of JHD against human colorectal carcinoma cells (SW480) and explore its mechanism. MTT assay showed that JHD decreased the cellular viability of SW480 cells in dose-dependent and time-dependent manner. Flow cytometry analysis revealed that JHD induced G0/G1-phase cell cycle arrest in SW480 cells and had a strong apoptosis-inducing effect on SW480 cells. Meanwhile it enhanced the expression of p27, cleaved PARP, cleaved caspase-3, and Bax and decreased the levels of PARP, caspase-3, Bcl-2, CDK2, CDK4, CDK6, cyclin D1, cyclin D2, cyclin D3, and cyclin E1, which was evidenced by RT-qPCR and Western blot analysis. In conclusion, these results indicated that JHD inhibited proliferation in SW480 cells by inducing G0/G1-phase cell cycle arrest and apoptosis, providing a practicaltherapeutic strategy against colorectal cancer.

\section{Introduction}

Colorectal cancer (CRC) is one of the most common malignant tumors, which is characterized by high morbidity and mortality [1]. At present, multiple chemotherapeutic drugs are widely used in the treatment of CRC, but their side effects hamper their clinical application and efficacy, such as neurotoxic effects and myelosuppression [2]. However, compared with chemotherapeutic drugs, natural products contain relatively fewer side effects and have been shown to possess beneficial therapeutic effects for cancer [3-5]. Therefore, it is necessary to develop naturally occurring agents against CRC.

According to the major precepts of traditional Chinese medicine (TCM), these Chinese formulas emphasize not only the symptoms but also restoring and maintaining the body homeostasis, which is very similar to the rationale of modern multitargeted therapeutics [6]. The Chinese herbal formula, Jianpi Huayu Decoction (JHD), contains Atractylodes macrocephala Koidz., Euphorbia humifusa Willd., Salvia miltiorrhiza Bunge., Paris polyphylla Sm., Curcuma phaeocaulis Val., Scutellaria barbata D. Don., and Artemisia capillaris Thunb. and has been well used against CRC in the clinical treatment, which can raise quality of life and decrease complications [7]. Previous studies proposed that extracts of JHD possess antitumor activity to suppress the growth of many types of cancer including CRC both in vitro and in vivo $[7,8]$. To further elucidate the precise mechanism of the potential tumoricidal activity of JHD, in this study, we investigated its antiproliferative activity against human colon adenocarcinoma SW480 cells and possible mechanisms of growth inhibition. 


\section{Materials and Methods}

2.1. Chemicals and Antibodies. RPMI 1640 and calf serum were purchased from HyClone (Thermo Scientific, USA). 3-(4,5-Dimethylthiazol-2-yl)-2,5-diphenyltetrazolium bromide (MTT) and monoclonal mouse $\beta$-actin antibody were purchased from Sigma Chemical Co. (St. Louis, MO). The antibodies against Bax, Bcl-2, cyclin D1, cyclin D2, cyclin D3, cyclin E1, CDK2, CDK4, CDK6, p27, caspase-3, cleaved caspase-3, PARP, and cleaved PARP and the horseradish peroxidase (HRP) labeled goat anti-mouse or anti-rabbit IgG antibody were purchased from Cell Signaling Technology (Beverly, MA). Annexin V-fluorescein isothiocyanate (FITC)/PI apoptosis detection kit and Cell Cycle Analysis kit were from BD Biosciences (San Diego, CA). TRIzol reagent and Power SYBR Green PCR Master Mix were from Life Technologies (Grand Island, NY). PrimeScript RT reagent Kit with gDNA Eraser was from TaKaRa (Dalian, China). All other chemicals were purchased from Sigma and Merck and were of the highest grade available.

2.2. Preparation of the JHD Extract. The herbs of the JHD extract (Atractylodes macrocephala Koidz. 10 g, Euphorbia humifusa Willd. $10 \mathrm{~g}$, Salvia miltiorrhiza Bunge. $15 \mathrm{~g}$, Paris polyphylla Sm. 15 g, Curcuma phaeocaulis Val. 10 g, Scutellaria barbata D. Don $30 \mathrm{~g}$, and Artemisia capillaris Thunb. $15 \mathrm{~g}$ ) were obtained from the Jiangsu Province Hospital of Traditional Chinese Medicine (Nanjing, China). The total weight of the dried herbs was $105 \mathrm{~g}$. First, the plants were blended in $1050 \mathrm{~mL}$ double-distilled water $(1: 10, \mathrm{w} / \mathrm{v})$ for $1 \mathrm{~h}$ and then heated to $100^{\circ} \mathrm{C}$ for $2 \mathrm{~h}$, after which the residue was boiled for $2 \mathrm{~h}$ with $1050 \mathrm{~mL}$ distilled water again. Next, the two extracts were mixed and concentrated to $1 \mathrm{~g}$ herb/mL and then filtered through a $0.2 \mu \mathrm{m}$ filter. The extract was stored at $-20^{\circ} \mathrm{C}$ until use.

2.3. Cell Lines and Cell Culture. The human colorectal carcinoma SW480 cells were provided by the Center Laboratory of the Jiangsu Province Hospital of Traditional Chinese Medicine (Nanjing, China), cultured in RPMI-1640 medium containing $10 \%$ bovine serum, penicillin $(100 \mathrm{U} / \mathrm{mL})$, and streptomycin $(100 \mu \mathrm{g} / \mathrm{mL})$ at $37^{\circ} \mathrm{C}$ in $5 \% \mathrm{CO}_{2}$ atmosphere.

2.4. MTT Assay. The SW480 cells in the logarithmic growth phase were seeded on the 96 -well plate at $8 \times 10^{3}$ cells/well and incubated overnight. After the cells were treated with JHD $(0$, $0.25,0.5,1,2,4$, and $8 \mathrm{mg} / \mathrm{mL}$ ) for $12 \mathrm{~h}, 24 \mathrm{~h}$, and $48 \mathrm{~h}$, the medium was discarded and treated with $20 \mu \mathrm{L} \mathrm{MTT}$ for $4 \mathrm{~h}$ at $37^{\circ} \mathrm{C}$. Cells were lysed in $150 \mu \mathrm{L}$ DMSO, and then the optical densities (ODs) were measured at $490 \mathrm{~nm}$ by using ELx800 microplate reader (BioTek, Winooski, VT). The cell growth inhibition rate was calculated using the following formula: Inhibition rate $=\left(1-\mathrm{OD}_{\text {experiment }} / \mathrm{OD}_{\text {control }}\right) \times 100 \%$.

2.5. Apoptosis Assay. The SW480 cells $\left(1 \times 10^{5}\right)$ were seeded into $60 \mathrm{~mm}$ Petri dish and incubated overnight. After treatment with or without JHD $(1,2,4 \mathrm{mg} / \mathrm{mL})$ for $24 \mathrm{~h}$, SW480 cells were harvested, washed twice with cold phosphate buffer saline (PBS), and resuspended in $1 \mathrm{x}$ binding buffer, to which
$5 \mu \mathrm{L}$ Annexin V-FITC and $5 \mu \mathrm{L}$ propidium iodide (PI) were added. The cells were gently vortexed and incubated for $15 \mathrm{~min}$ at room temperature in the dark and then analyzed by flow cytometry (FCM).

2.6. Cell Cycle Analysis. The SW480 cells $\left(1 \times 10^{6}\right)$ were seeded into $100 \mathrm{~mm}$ Petri dish and incubated overnight. After synchronization by changing the media with a serumfree media for $24 \mathrm{~h}$, the cells were then treated with or without JHD $(1,2,4 \mathrm{mg} / \mathrm{mL})$ for $24 \mathrm{~h}$. Next, the cells were harvested, washed with cold PBS, and then fixed with $70 \%$ cold ethanol at $4^{\circ} \mathrm{C}$ overnight. After being washed twice with cold PBS, fixed cells were resuspended with $100 \mu \mathrm{g} / \mathrm{mL}$ RNase, incubated with $50 \mu \mathrm{g} / \mathrm{mL}$ PI at $37^{\circ} \mathrm{C}$ for $30 \mathrm{~min}$ in the dark room, and analyzed by FCM.

2.7. RT-qPCR Analysis. The SW480 cells $\left(8 \times 10^{5}\right)$ were seeded into $60 \mathrm{~mm}$ Petri dish and incubated overnight. After treatment with or without JHD $(1,2,4 \mathrm{mg} / \mathrm{mL})$ for $24 \mathrm{~h}$, the total RNA was isolated using TRIzol reagent and reversetranscribed into cDNA using the TaKaRa RT reagent kit. The PCR reactions were quantified by ABI 7500 fast RTqPCR System. The sequences of the primers were provided in Table 1. Each sample was tested in triplicate. Cycle threshold $(\mathrm{Ct})$ values were obtained graphically for the target genes and GAPDH. $\Delta \mathrm{Ct}=\mathrm{Ct}_{\text {target genes }}-\mathrm{Ct}_{\mathrm{GAPDH}} \cdot \Delta \Delta \mathrm{Ct}=$ $\Delta \mathrm{Ct}_{\text {treated samples }}-\Delta \mathrm{C}_{\text {tcontrol samples }}$. The relative fold change in gene expression was calculated as $2^{-\Delta \Delta \mathrm{CT}}$.

2.8. Western Blot Analysis. The SW480 cells $\left(2 \times 10^{6}\right)$ were seeded into $100 \mathrm{~mm}$ Petri dish and incubated overnight. After treatment with or without $\operatorname{JHD}(1,2,4 \mathrm{mg} / \mathrm{mL})$ for $24 \mathrm{~h}$, SW480 cells were washed twice with cold PBS, lysed in RIPA buffer containing protease inhibitor cocktail (P8340, Sigma-Aldrich) for $30 \mathrm{~min}$ on ice, and then harvested by using cell scraper. Cell lysates were centrifuged at $12000 \mathrm{~g}$ for $15 \mathrm{~min}$ at $4^{\circ} \mathrm{C}$. Protein concentrations were determined by the Bradford method. Samples containing equal proteins $(20 \mu \mathrm{g})$ were loaded and analyzed by Western blot assay. Briefly, proteins were separated by $10 \%$ sodium dodecyl sulfate polyacrylamide gel electrophoresis (SDS-PAGE) and transferred onto polyvinylidene fluoride (PVDF) membrane (Millipore, Billerica, MA). Membrane were washed by Trisbuffered saline Tween (TBST, $20 \mathrm{mM}$ Tris- $\mathrm{HCl}, \mathrm{pH} \mathrm{7.6}$, $150 \mathrm{mM} \mathrm{NaCl}$, and $0.01 \%$ Tween-20) for $5 \mathrm{~min}$ and incubated with blocking buffer (TBST containing $50 \mathrm{~g} / \mathrm{L}$ BSA) for at least $1 \mathrm{~h}$ at room temperature. Membranes were incubated with desired primary antibody Bax, Bcl-2, cyclin D1, cyclin D2, cyclin D3, cyclin E1, CDK2, CDK4, CDK6, p27, caspase3 , cleaved caspase-3, PARP, cleaved PARP (at a dilution of $1: 1,000$ ), and $\beta$-actin (at a dilution of $1: 5,000$ ) overnight at $4^{\circ} \mathrm{C}$. Then, membranes were washed in TBST for $5 \mathrm{~min}$ three times and incubated with HRP-linked secondary antibodies (anti-rabbit or anti-mouse IgG, at a dilution of $1: 1,000$ ) for $1 \mathrm{~h}$ at room temperature. After the membranes were washed for $5 \mathrm{~min}$ three times with TBST, the signals were detected by an ECL detection kit (Millipore, Billerica, MA). $\beta$-actin was used as a loading control. 
TABLE 1: Sequences of primers used in the real-time qPCR amplifications.

\begin{tabular}{|c|c|c|}
\hline Gene & Primer sequences $\left(5^{\prime}-3^{\prime}\right)$ & Length of PCR product (bp) \\
\hline \multirow{2}{*}{ Cyclin D1 } & F: ACCTGAGGAGCCCCAACAAC & \multirow{2}{*}{112} \\
\hline & R: GCTTCGATCTGCTCCTGGC & \\
\hline \multirow{2}{*}{ Cyclin E1 } & F: GTCCTGGATGTTGACTGCCTTGA & \multirow{2}{*}{258} \\
\hline & R: GTCCAGCAAATCCAAGCTGTCTC & \\
\hline \multirow{2}{*}{$\mathrm{CDK} 2$} & F: GTCCAGCAAATCCAAGCTGTCTC & \multirow{2}{*}{237} \\
\hline & R: CTGCTCTCACTGGCATTCCT & \\
\hline \multirow{2}{*}{ CDK4 } & F: CTCTCTAGCTTGCGGCCTG & \multirow{2}{*}{209} \\
\hline & R: GGCACCGACACCAATTTCAG & \\
\hline \multirow{2}{*}{ CDK6 } & F: CTGCAGGGAAAGAAAAGTGC & \multirow{2}{*}{95} \\
\hline & R: CTCCTCGAAGCGAAGTCCTC & \\
\hline \multirow{2}{*}{$\mathrm{p} 27$} & F: TGCAACCGACGATTCTTCTACTCAA & \multirow{2}{*}{185} \\
\hline & R: CAAGCAGTGATGTATCTGATAAACAAGGA & \\
\hline \multirow{2}{*}{ Bax } & F: TTTGCTTCAGGGTTTCATCC & \multirow{2}{*}{213} \\
\hline & R: GCCACTCGGAAAAAGACCTC & \\
\hline \multirow{2}{*}{$\mathrm{Bcl}-2$} & F: TCGCCCTGTGGATGACTGAG & \multirow{2}{*}{143} \\
\hline & R: CAGAGTCTTCAGAGACAGCCAGGA & \\
\hline \multirow{2}{*}{ GAPDH } & F: AGCCACATCGCTCAGACAC & \multirow{2}{*}{66} \\
\hline & R: GCCCAATACGACCAAATCC & \\
\hline
\end{tabular}

2.9. Statistical Analysis. All data were evaluated using analysis of one-way ANOVA test with SPSS 19.0 which were expressed as the mean \pm standard deviation (SD). Significant differences between the control and treated cells were defined as $P<0.05$ or 0.01 .

\section{Results}

3.1. JHD Suppressed SW480 Cells Proliferation In Vitro. We first examined the effect of JHD on SW480 cell viability by MTT assay. As shown in Figure 1(a), after treatment with JHD $(0,0.25,0.5,1,2,4$, and $8 \mathrm{mg} / \mathrm{mL})$ for $12 \mathrm{~h}, 24 \mathrm{~h}$, and $48 \mathrm{~h}$, the inhibition rates of the cells increased significantly compared to untreated control cells $(P<0.01$ or 0.05$)$. These results suggested that JHD inhibited the proliferation of SW480 cells in dose-dependent and time-dependent manner.

3.2. JHD Induced SW480 Cells Apoptosis. To further confirm the apoptosis of JHD, SW480 cells were stained with Annexin V/PI and subsequently analyzed by FCM after treatment with or without JHD $(1,2$, and $4 \mathrm{mg} / \mathrm{mL})$ for $24 \mathrm{~h}$. As shown in Figure 1(d), from 0 to $4 \mathrm{mg} / \mathrm{mL}$, early apoptosis rates of SW480 cells increased from $3.7 \pm 0.56 \%$ to $32.5 \pm 2.12 \%$. In summary, the above results suggested that JHD could effectively induce apoptosis, and the apoptosis rates presented a dose-dependent manner.

3.3. JHD Induced G0/G1-Phase Cell Cycle Arrest in SW480 Cells. To further confirm the effect of JHD on cell cycle, SW480 cells were evaluated by FACS analysis with PI staining after treatment with or without JHD $(1,2,4 \mathrm{mg} / \mathrm{mL})$ for $24 \mathrm{~h}$. As shown in Figures 1(b) and 1(c), from 0 to $4 \mathrm{mg} / \mathrm{mL}$, the percentage of SW480 cells in G0/G1-phase increased from $39.76 \pm 3.21 \%$ to $56.74 \pm 2.62 \%$, suggesting that JHD induced
G0/G1-phase cell cycle arrest in SW480 cells in a dosedependent manner.

3.4. JHD Altered the Expression of Cell Cycle Regulatory and Apoptotic Factors in SW480 Cells. To evaluate levels of cell cycle regulatory proteins and apoptotic factors, the expression levels were analyzed by RT-qPCR and Western blot analysis. As shown in Figure 2, JHD treatment significantly enhanced the expression levels of p27, Bax, cleaved caspase-3, and cleaved PARP and suppressed the expression levels of Bcl2, cyclin D1, cyclin D2, cyclin D3, cyclin E1, CDK2, CDK4, CDK6, PARP, and caspase- 3 in SW480 cells in a dosedependent manner.

\section{Discussion}

TCM has been used in China to treat a variety of diseases including cancer. At present, TCM has gained increasing attention on its usage as an antitumor treatment, which is considered to be a multitarget agent that exerts therapeutic function in a holistic way. JHD has been well used against $\mathrm{CRC}$ in the clinical treatment, which can raise quality of life and decrease complications. To further elucidate the antitumor mechanism of JHD, herein we investigated its effect on the proliferation of human colon carcinoma SW480 cells in vitro.

Here we found that JHD inhibited proliferation of SW480 cells in dose-dependent and time-dependent manner. And JHD effectively induced apoptosis and G0/G1-phase cell cycle arrest, which presented a dose-dependent manner. Furthermore, RT-qPCR and Western blot analysis showed that JHD treatment significantly enhanced the expression levels of p27, Bax, cleaved caspase-3, and cleaved PARP and suppressed the expression levels of Bcl-2, cyclin D1, cyclin 

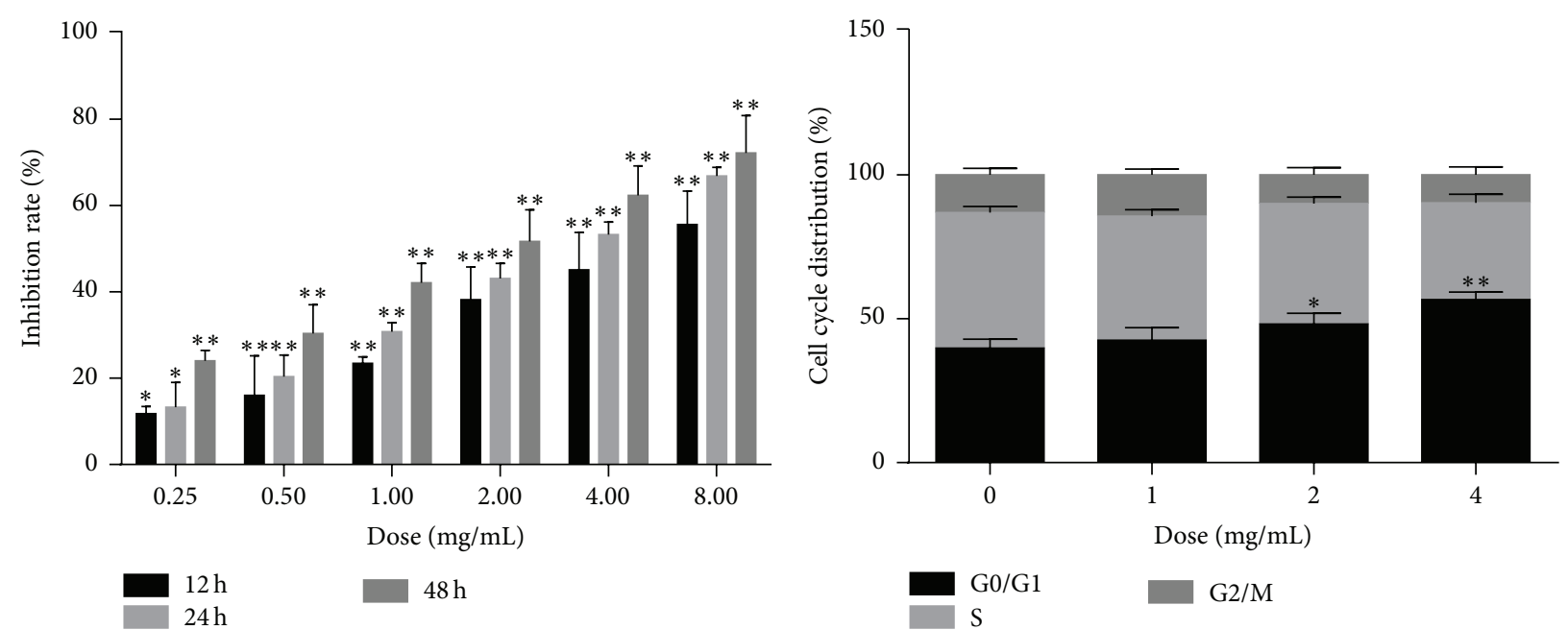

(a)
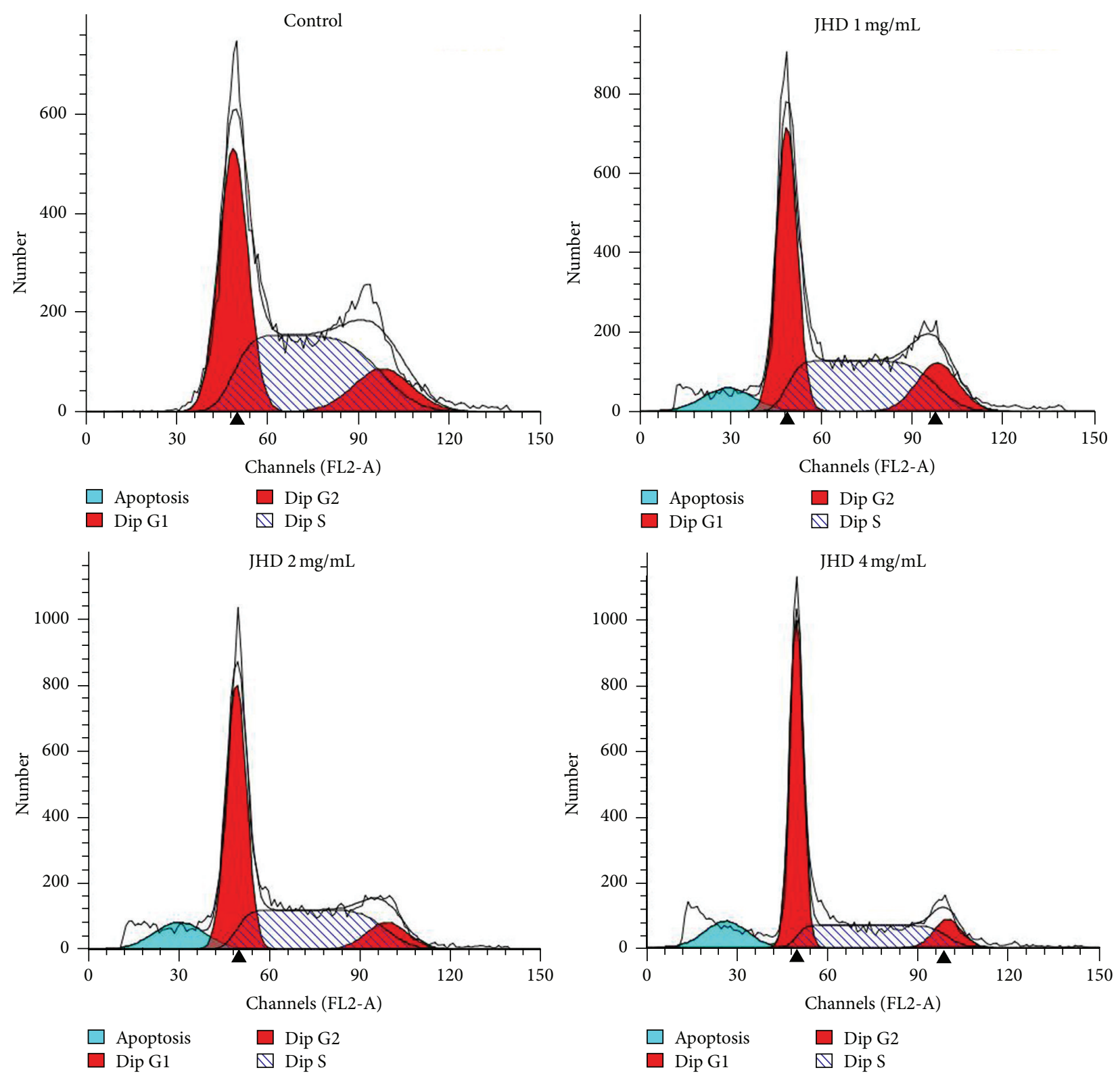

(c)

Figure 1: Continued. 

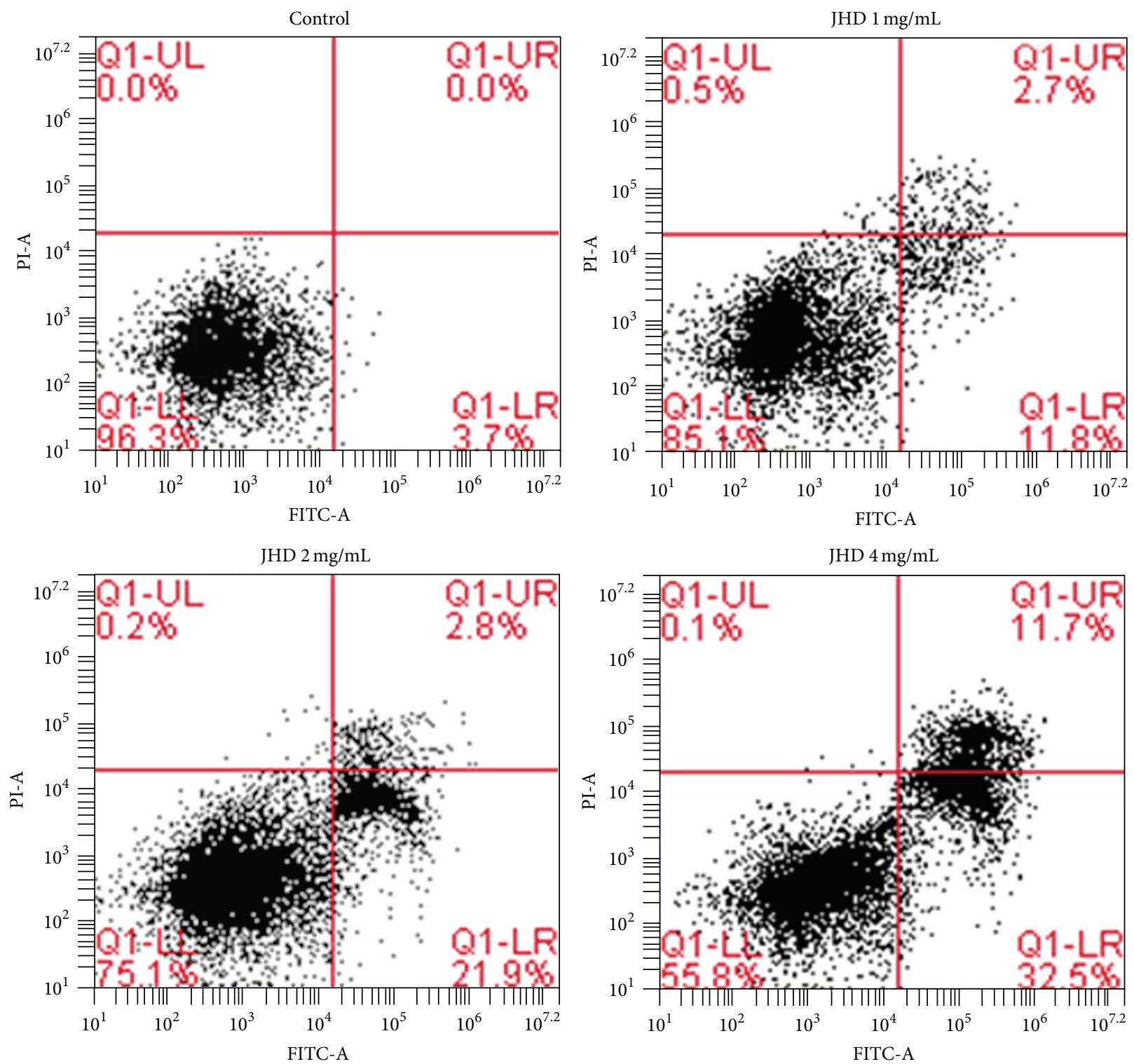

(d)

FIGURE 1: (a) The effect of JHD on the viability of SW480 cells. Cells were treated with different concentrations of JHD and for $12 \mathrm{~h}, 24 \mathrm{~h}$, or $48 \mathrm{~h}$. The bars indicate standard errors. The asterisk indicates a significant increase in the inhibition rate between groups treated with JHD and the untreated control group. Data are expressed as the mean \pm SD of three experiments $\left({ }^{*} P<0.05,{ }^{* *} P<0.01\right)$. (b) and (c) The effect of JHD on cell cycle in SW480 cells. SW480 cells were treated with different concentration of JHD for $24 \mathrm{~h}$. At the end of treatment, cells were trypsinized, incubated with RNase, stained with propidium iodide (PI), and analyzed by FCM. Data are expressed as the mean \pm SD of three experiments. ${ }^{*} P<0.05,{ }^{* *} P<0.01$, versus control cells. (d) The apoptosis induced by JHD in SW480 cells. Cultures of SW480 cells were treated with different concentration of JHD for $24 \mathrm{~h}$ harvested by trypsinization and centrifugation and then analyzed by flow cytometry after staining with annexin V-FITC and propidium iodide. Results shown are of an experiment representative of apoptosis. Q1-UL showed that cells were undergoing necrosis, and Q1-UR showed that cells were at the end stage of apoptosis. Q1-LL showed that cells were viable, or there was no measurable apoptosis. Q1-LR showed that cells were undergoing apoptosis.

D2, cyclin D3, cyclin E1, CDK2, CDK4, CDK6, PARP, and caspase-3 in SW480 cells in a dose-dependent manner.

Numerous reports suggest that there is a strong link between cell cycle deregulation and carcinogenesis [9]. And deregulated growth is a unique characteristic of cancer cells and a primary requirement for processes in cancer progression [10]. Cellular proliferation is regulated primarily by the regulation of cell cycle to monitor DNA integrity [11], which consists of four distinct sequential phases (G0/G1, S, G2, and M) [12]. In eukaryotes, the cell cycle is regulated by cyclins, cyclin-dependent kinases (CDKs), and cyclindependent kinase inhibitors (CDKIs) [13]. The levels of CDKs remain constant during the cell cycle, whereas the levels of cyclins fluctuate, and the phases of the cell cycle are controlled 

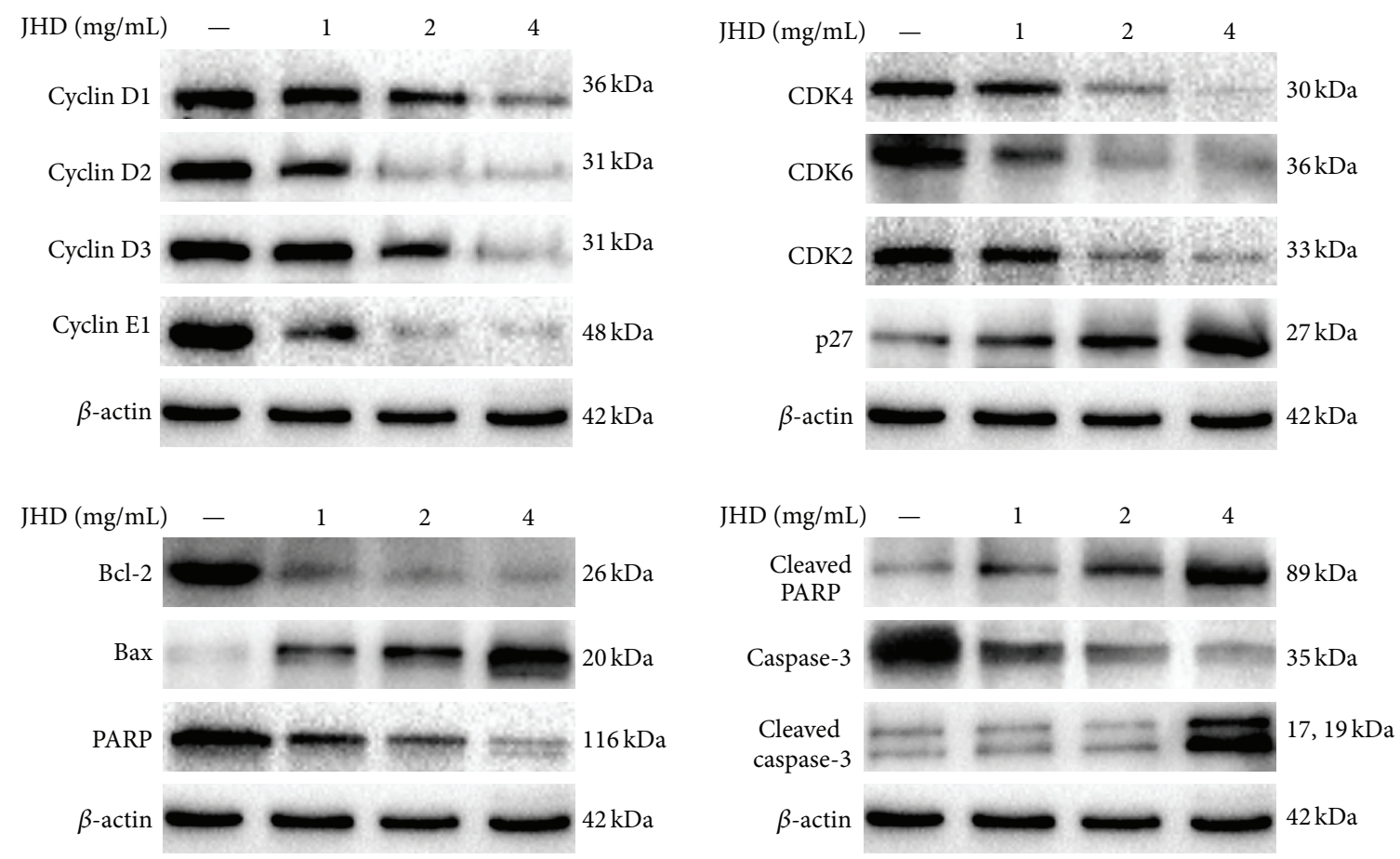

(a)

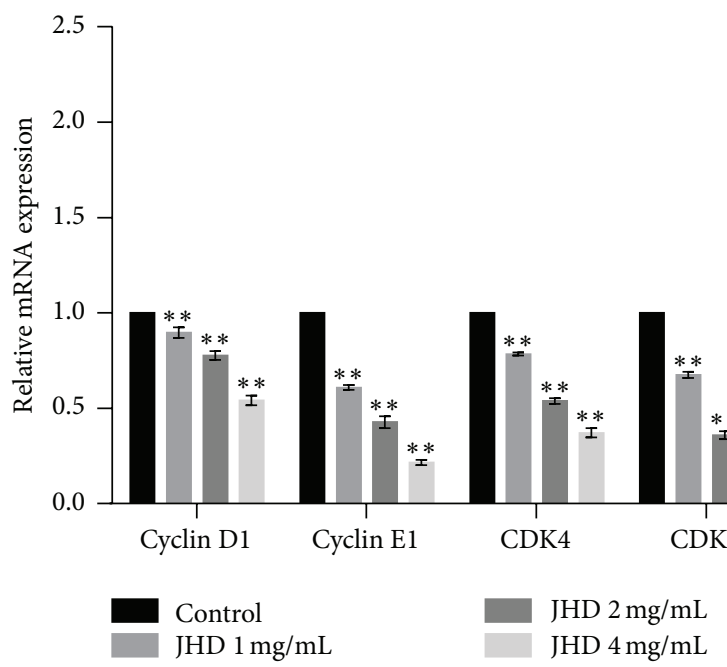

(b)

FIGURE 2: The effect of JHD on the expression of the cell cycle and apoptosis associated molecules in SW480 cells. Cells were treated with various concentrations of JHD for $24 \mathrm{~h}$. (a) The protein levels of cyclin D1, cyclin D2, cyclin D3, cyclin E1, CDK2, CDK4, CDK6, p27, Bax, Bcl-2, PARP, cleaved PARP, caspase-3, and cleaved caspase-3 were determined by Western blotting. (b) The mRNA levels of cyclin D1, cyclin E1, CDK2, CDK4, CDK6, p27, Bax, and Bcl-2 were determined by RT-PCR. ${ }^{*} P<0.05,{ }^{* *} P<0.01$, versus control cells. GAPDH and $\beta$-actin were used as the internal controls for the RT-PCR or Western blot assays.

by the activation of different CDK/cyclin complexes [14], the importance of which in cell proliferation is supported by the finding that deregulation of $\mathrm{CDK} /$ cyclin complex activity is observed in a variety of human tumors [15]. At different phases, passage through the cell cycle is governed by sequential activation and subsequent inactivation of a series of CDKs, whose activity depends on interactions with timely expressed cyclins and CDKIs [16]. Cell cycle arrest in response to stress is integral to the maintenance of genomic integrity, which occurs due to the loss of cyclin expression and CDK activity [17]. The control mechanisms that restrain cell cycle transition or induce apoptotic signaling pathways after cell stress are known as cell cycle checkpoints [18]. By using FCM analysis we found that the inhibitory effect of JHD on SW480 cell proliferation was associated with the blockage of G1 to $S$ progression. As one of the main checkpoints of cell cycle, G1/S transition is responsible for initiation and completion of DNA replication, which is 
strongly regulated by the combined activity of the cyclin D/CDK4, cyclin D/CDK6, and cyclin E/CDK2 complex [1921]. The proliferation inhibitor p27 plays an inhibitory role in G1/S progression by inhibiting the activity of cyclin/CDK complexes [22]. As shown in Figure 2, JHD upregulated the expression of p27 and downregulated the expression of cyclin D1, cyclin D2, cyclin D3, cyclin E1, CDK4, CDK6, and CDK2 in SW480 cells.

Apoptosis is a process of programmed cell death, which plays a crucial role in maintaining cellular homeostasis between cell division and cell death [23]. Caspase-cascade is a central part of cell apoptosis and regulated by various kinds of molecules, such as Bcl-2 family proteins. Generally, the caspase family proteases can be activated through two pathways: one is the death signal-induced, death receptor mediated pathway; the other is the mitochondrion-dependent pathway $[24,25]$. Caspase- 3 is the key enzyme required in the caspase cascade activation and execution [26]. Once the specificity substrate such as PARP has been cut by the cleavage of caspases, apoptosis will be induced [27, 28]. The present research used FCM to detect cell apoptosis rate, finding the apoptosis rates of SW480 cells being increased significantly when treated with JHD for $24 \mathrm{~h}$. Further Western blot data revealed that the caspase- 3 , cleaved caspase-3, PARP, and cleaved PARP were activated by JHD, which indicated the cell apoptosis. Therefore, we inferred that activating caspase cascade is the mechanism of JHD inducing cell apoptosis. However, more research is in need to investigate JHD inducing the apoptosis of SW480 cells through endogenous pathways or exogenous pathways or through both. Although the caspase-cascade is a central point to apoptosis, its activation is regulated by many other factors, among which Bcl-2 family plays a pivotal role in either inhibiting (Bcl-2) or promoting (Bax) cell death $[29,30]$. Recently, it has been reported that Bax inactivating $\mathrm{Bcl}-2$ proteins regulates the apoptosis mediated by mitochondria and the ratio of $\mathrm{Bax}$ to $\mathrm{Bcl}-2$ proteins increases during apoptosis induction [31]. Therefore, we continued to detect the expression change of Bcl-2 family. As shown in Figure 2, the protein level of Bax increased in a dose-dependent manner, while the $\mathrm{Bcl}-2$ protein decreased.

\section{Conclusion}

According to the above results, we found that JHD could inhibit proliferation of SW 480 cells by inducing G0/G1-phase cell cycle arrest and apoptosis. Its induction of apoptosis may activate the caspase-cascades and upregulate the expression of Bax and downregulate the expression of Bcl-2. JHD could induce G0/G1-phase cell cycle arrest of SW480 cells. Its molecular mechanism may lie on upregulating the expression of p27 and downregulating the expression of cyclin D1, cyclin D2, cyclin D3, cyclin E1, CDK4, CDK6, and CDK2. These findings provide an experiment basis for JHD as chemotherapy drugs against CRC cells, thereby facilitating the development of new anticancer agents.

\section{Conflict of Interests}

The authors declare that there is no conflict of interests regarding the publication of this paper.

\section{Acknowledgments}

This work was funded by the Priority Academic Program Development of Jiangsu Higher Education Institutions (PAPD), Special Grants for Leading Principal Investigators (LJ200908) from Jiangsu Administration of Traditional Chinese Medicine, and State Administration of Traditional Chinese Medicine of People's Republic of China (JDZX2012087).

\section{References}

[1] A. Jemal, F. Bray, M. M. Center, J. Ferlay, E. Ward, and D. Forman, "Global cancer statistics," CA: A Cancer Journal for Clinicians, vol. 61, no. 2, pp. 69-90, 2011.

[2] Q. Li, S. Y. Zhou, J. Jing et al., "Oligosaccharide from apple induces apoptosis and cell cycle arrest in HT29 human colon cancer cells," International Journal of Biological Macromolecules, vol. 57, pp. 245-254, 2013.

[3] M. Gordaliza, "Natural products as leads to anticancer drugs," Clinical and Translational Oncology, vol. 9, no. 12, pp. 767-776, 2007.

[4] A. L. Harvey, "Natural products in drug discovery," Drug Discovery Today, vol. 13, no. 19-20, pp. 894-901, 2008.

[5] D. J. Newman, G. M. Cragg, and K. M. Snader, "The influence of natural products upon drug discovery," Natural Product Reports, vol. 17, no. 3, pp. 215-234, 2000.

[6] X.-Y. Tian and L. Liu, "Drug discovery enters a new era with multi-target intervention strategy," Chinese Journal of Integrative Medicine, vol. 18, no. 7, pp. 539-542, 2012.

[7] X. Zou, R. P. Wang, D. Li et al., "Effects serum with Jianpi Huayu prescription on apoptosis of human colon cancer cell lovo," Liaoning Journal of Traditional Chinese Medicine, vol. 38, no. 12, pp. 2355-2356, 2011.

[8] B. F. Ling, R. P. Wang, X. Zou et al., "Experimental study of Jianpi Huayu decoction on the effect of subcutaneous transplanted tumor and correlative MicroRNAs expression of nude mice," Journal of Sichuan Traditional Chinese Medicine, vol. 30, no. 8, pp. 49-52, 2012.

[9] G. Nguyen-Ba and P. Vasseur, "Epigenetic events during the process of cell transformation induced by carcinogens (review)," Oncology Reports, vol. 6, no. 4, pp. 925-932, 1999.

[10] K. Vermeulen, D. R. Van Bockstaele, and Z. N. Berneman, “The cell cycle: a review of regulation, deregulation and therapeutic targets in cancer," Cell Proliferation, vol. 36, no. 3, pp. 131-149, 2003.

[11] G. Brooks and N. B. La Thangue, "The cell cycle and drug discovery: the promise and the hope," Drug Discovery Today, vol. 4, no. 10, pp. 455-464, 1999.

[12] R. Suryadinata, M. Sadowski, and B. Sarcevic, "Control of cell cycle progression by phosphorylation of cyclin-dependent kinase (CDK) substrates," Bioscience Reports, vol. 30, no. 4, pp. 243-255, 2010.

[13] J. P. Li, Y. X. Yang, Q. L. Liu et al., “The investigational Aurora kinase A inhibitor alisertib (MLN8237) induces cell cycle $\mathrm{G}_{2} / \mathrm{M}$ arrest, apoptosis, and autophagy via p38 MAPK and Akt/mTOR signaling pathways in human breast cancer cells," Drug Design, Development and Therapy, vol. 9, pp. 1627-1652, 2015.

[14] M. Malumbres and M. Barbacid, "Cell cycle, CDKs and cancer: a changing paradigm," Nature Reviews Cancer, vol. 9, no. 3, pp. 153-166, 2009. 
[15] D. E. Lee, K. Lee, S. K. Jung et al., “6,7,4'-Trihydroxyisoflavone inhibits HCT-116 human colon cancer cell proliferation by targeting CDK1 and CDK2," Carcinogenesis, vol. 32, no. 4, pp. 629-635, 2011.

[16] S. H. Lim and P. Kaldis, "Cdks, cyclins and CKIs: roles beyond cell cycle regulation," Development, vol. 140, no. 15, pp. 30793093, 2013.

[17] L. Zhang, Y. Zheng, H. Deng, L. Liang, and J. Peng, "Aloperine induces G2/M phase cell cycle arrest and apoptosis in HCT116 human colon cancer cells," International Journal of Molecular Medicine, vol. 33, no. 6, pp. 1613-1620, 2014.

[18] P. M. Flatt and J. A. Pietenpol, "Mechanisms of cell-cycle checkpoints: at the crossroads of carcinogenesis and drug discovery," Drug Metabolism Reviews, vol. 32, no. 3-4, pp. 283$305,2000$.

[19] J. Massagué, “G1 cell-cycle control and cancer," Nature, vol. 432, no. 7015, pp. 298-306, 2004.

[20] J. Cicenas, K. Kalyan, A. Sorokinas et al., "Highlights of the latest advances in research on CDK inhibitors," Cancers, vol. 6, no. 4, pp. 2224-2242, 2014.

[21] L. Wei, J. Lin, G. Wu et al., "Scutellaria barbata D. Don induces G1/S arrest via modulation of p53 and Akt pathways in human colon carcinoma cells," Oncology Reports, vol. 29, no. 4, pp. 1623-1628, 2013.

[22] D. A. Orlando, C. Y. Lin, A. Bernard et al., "Global control of cell-cycle transcription by coupled CDK and network oscillators," Nature, vol. 453, no. 7197, pp. 944-947, 2008.

[23] N. A. Thornberry and Y. Lazebnik, "Caspases: enemies within," Science, vol. 281, no. 5381, pp. 1312-1316, 1998.

[24] A. Degterev and J. Yuan, "Expansion and evolution of cell death programmes," Nature Reviews Molecular Cell Biology, vol. 9, no. 5, pp. 378-390, 2008.

[25] J. B. Denault and K. Boatright, "Apoptosis in biochemistry and structural biology," IDrugs, vol. 7, no. 4, pp. 315-317, 2004.

[26] T.-J. Fan, L.-H. Han, R.-S. Cong, and J. Liang, "Caspase family proteases and apoptosis," Acta Biochimica et Biophysica Sinica, vol. 37, no. 11, pp. 719-727, 2005.

[27] S. Ghavami, M. Hashemi, S. R. Ande et al., "Apoptosis and cancer: mutations within caspase genes," Journal of Medical Genetics, vol. 46, no. 8, pp. 497-510, 2009.

[28] R. Matuo, F. G. Sousa, A. E. Escargueil et al., "5-Fluorouracil and its active metabolite FdUMP cause DNA damage in human SW620 colon adenocarcinoma cell line," Journal of Applied Toxicology, vol. 29, no. 4, pp. 308-316, 2009.

[29] C. Yu, S.-L. Liu, M.-H. Qi, X. Zou, J. Wu, and J. Zhang, "Herbal medicine Guan Chang Fu Fang enhances 5-fluorouracil cytotoxicity and affects drug-associated genes in human colorectal carcinoma cells," Oncology Letters, vol. 9, no. 2, pp. 701-708, 2015.

[30] J. K. Brunelle and A. Letai, "Control of mitochondrial apoptosis by the Bcl-2 family," Journal of Cell Science, vol. 122, no. 4, pp. 437-441, 2009.

[31] S. Salakou, D. Kardamakis, A. C. Tsamandas et al., "Increased bax/bcl-2 ratio up-regulates caspase- 3 and increases apoptosis in the thymus of patients with myasthenia gravis," In Vivo, vol. 21, no. 1, pp. 123-132, 2007. 


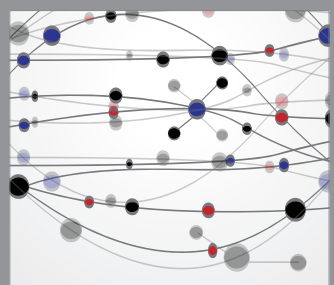

The Scientific World Journal
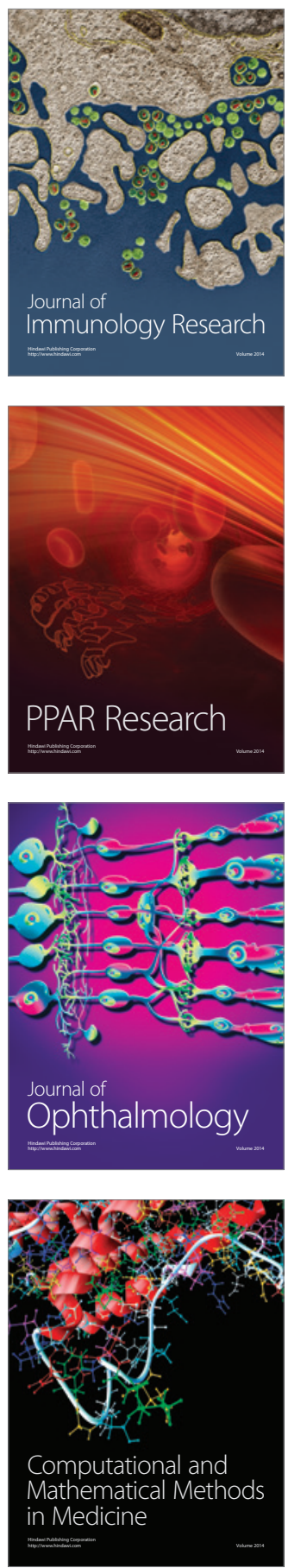

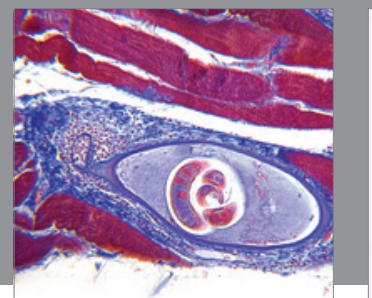

Gastroenterology

Research and Practice
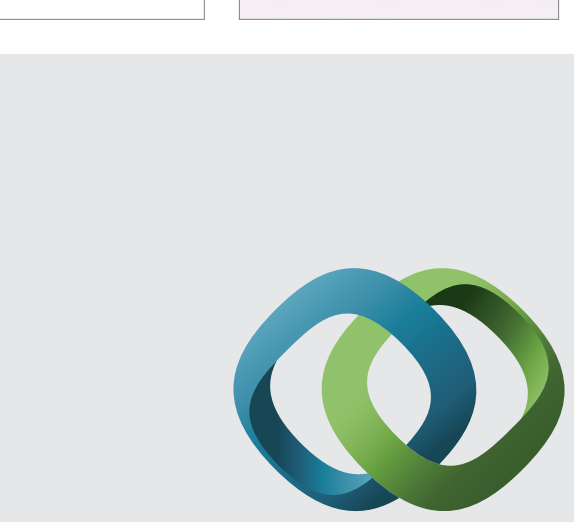

\section{Hindawi}

Submit your manuscripts at

http://www.hindawi.com
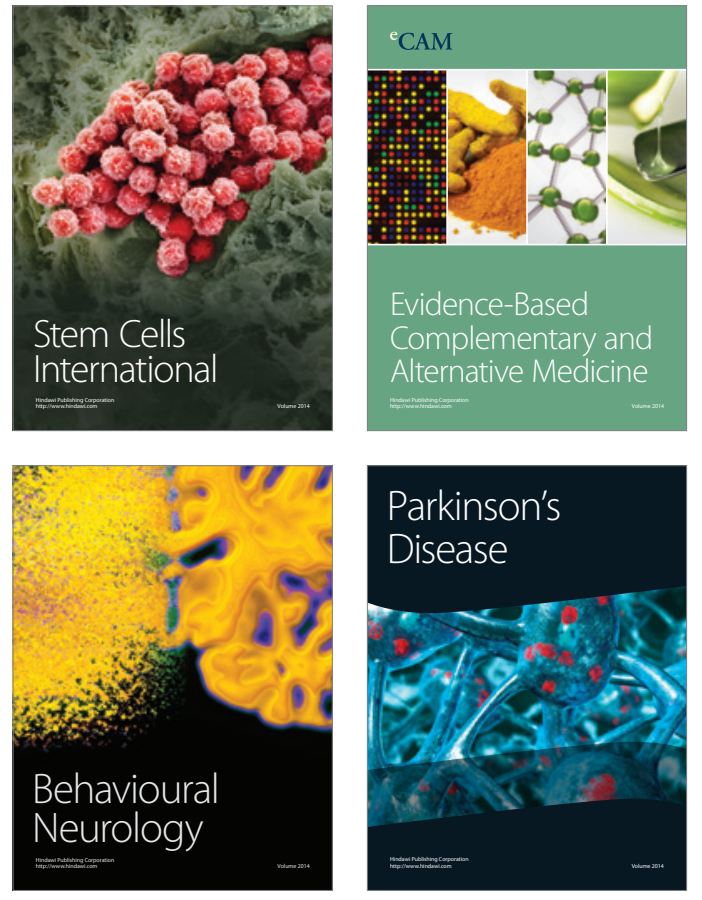
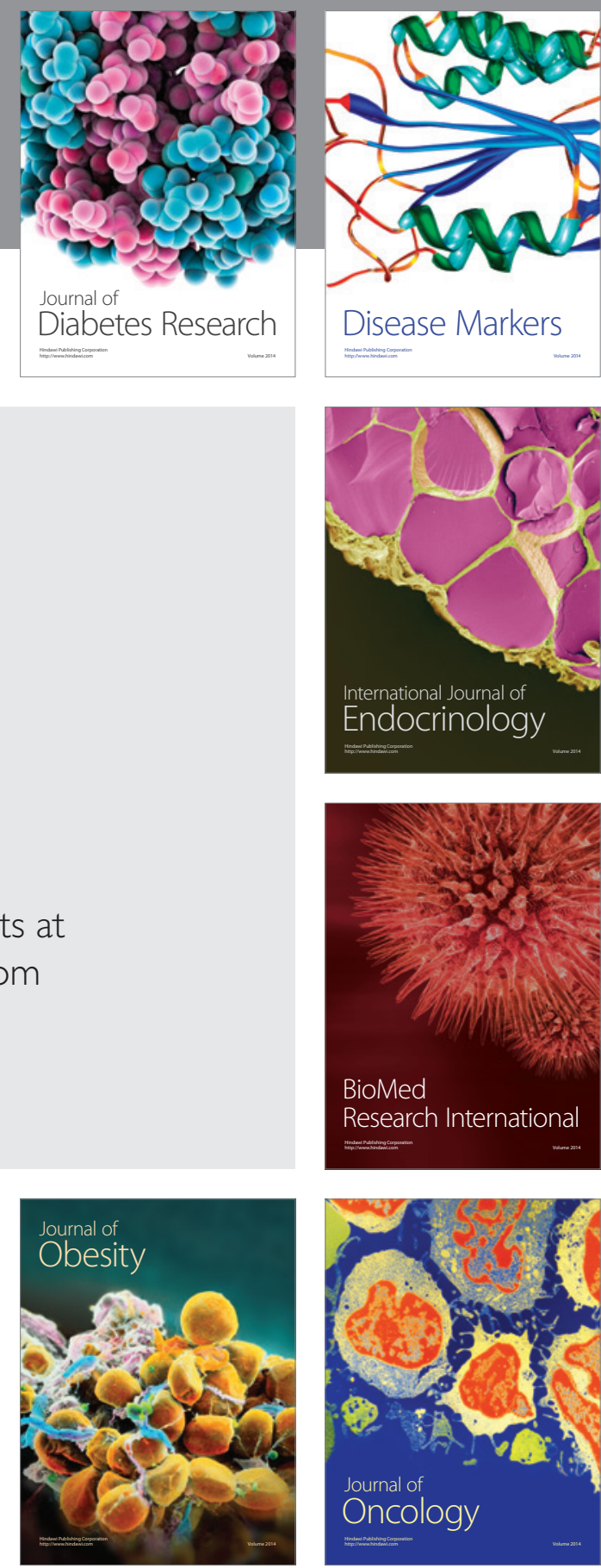

Disease Markers
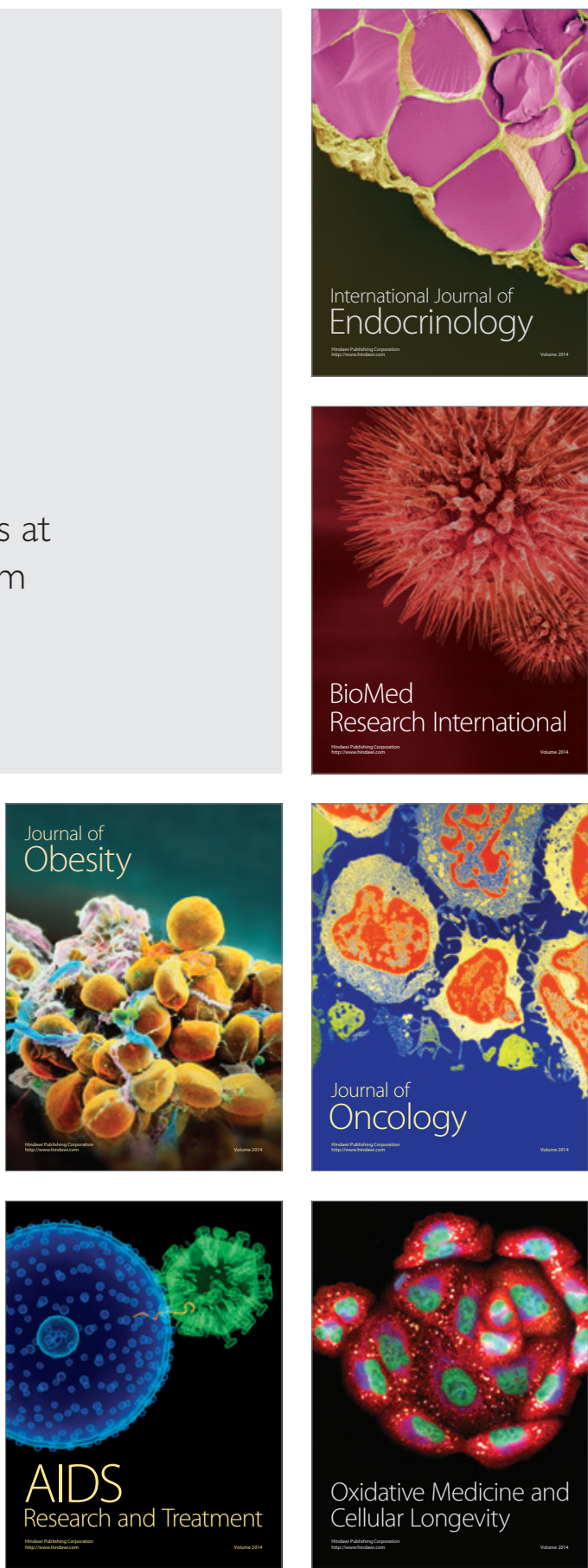